\title{
The Developmental Psychopathology of Stress Exposure in
}

\section{Childhood}

Jenalee R. Doom and Dante Cicchetti

In Harkness, K., \& Hayden, E.P. (Eds.) The Oxford Handbook of Stress and Mental Health. Oxford University Press.

\begin{abstract}
This chapter reviews how the field of developmental psychopathology has shaped research on risk and resilience processes in the context of childhood stress. The central tenets of developmental psychopathology, including its transdisciplinary and multilevel nature, equifinality and multifinality, developmental cascades, and the interaction of risk and protective factors across development, guide research aiming to understand individual differences in response to stressors during childhood. Various stressors that children experience, including maltreatment, poverty, institutional care, malnutrition, and environmental exposures, can lead to different effects on biology and behavior depending on the type, timing, chronicity, and severity of the stressor. Genetics, psychobiology, and neurophysiology have been incorporated into this research to enhance our understanding of individual differences in functioning following childhood stress. Future directions include more fully incorporating sex differences into studies of childhood stress and utilizing research in this area to create effective interventions for children experiencing severe stress.
\end{abstract}

Keywords: developmental psychopathology, stress, childhood, resilience, genetics, psychobiology, transdisciplinary, multilevel, individual differences 
Chronic, severe stress in childhood is associated with greater risk of cognitive, emotional, behavioral, and health problems, and an increased risk of psychopathology throughout the life span (Lupien, McEwen, Gunnar, \& Heim, 2009; Shonkoff, Boyce, \& McEwen, 2009); see December 2017 special issue of Development and Psychopathology entitled "Biological and Behavioral Effects of Early Adversity on Multiple Levels of Development"). However, there are significant individual differences in outcomes following chronic stress. Some individuals start on trajectories toward emotional or behavior problems while some do remarkably well despite a harsh early environment (Masten \& Cicchetti, 2016). Researchers have made a great deal of progress in the past few decades documenting how stress affects development, understanding the mechanisms by which stress affects development, and describing factors that foster resilience in the face of stress. This progress has largely been guided within the framework of developmental psychopathology. Despite this progress, there are many remaining questions that we need to answer in order to fully understand processes of risk and resilience (Masten \& Cicchetti, 2016).

This chapter is not a comprehensive review of research on the effects of stress on development and risk for psychopathology. However, we will provide an overview of the developmental psychopathology framework and major research areas addressing childhood stress exposure that have been guided by the framework. First, we will briefly review the tenets of developmental psychopathology and a few theories and models that have informed or been informed by developmental psychopathology. Then, we will outline different types of childhood stress that have profound impacts on development, viewed from a developmental psychopathology perspective. The influence of genetics in 
relation to childhood stress will then be discussed. The timing and chronicity of early stress will be considered in relation to the specific effects of these stressors, as well as the concept of resilience in the context of stress. Finally, we will consider sex differences in response to childhood stress and focus on unanswered questions and important future directions for research in order to improve the lives of children, adolescents, and adults who have experienced early stress.

\section{Tenets of Developmental Psychopathology}

The developmental psychopathology framework guides research and intervention work that aims to elucidate the developmental mechanisms that underlie normal and abnormal development to prevent and treat psychopathology (Cicchetti, 2016a, 2016b, 2016c, 2016d). This framework sets forth main tenets that guide the field, including the transdisciplinary and multilevel nature of developmental psychopathology, equifinality and multifinality, cascading effects across development, the interaction of risk and protective factors, and the consideration of context in determining adaptation versus maladaptation.

First, developmental psychopathology is inherently transdisciplinary. It is impossible to fully understand an individual's functioning and developmental trajectory by an analysis from one discipline. Psychology alone is not equipped to answer questions about changes in molecular biology that may affect current and future functioning; likewise, molecular biologists cannot assess current psychosocial functioning and pathways to adaptive or maladaptive psychological functioning solely through analysis at the micro level. However, contributions of these and other disciplines are needed to assemble the pieces of the puzzle that is human development. As individual disciplines 
accumulate more knowledge about normal and abnormal development, the field has grown increasingly interdisciplinary and collaborative in nature in order to create models that more accurately characterize pathways from early stress to later functioning. Likewise, interdisciplinary work informs prevention and intervention efforts by broadly and deeply assessing individual functioning and considering the multitude of individual and environmental factors that may influence intervention effectiveness.

Developmental psychopathology broadly transcends a multitude of disciplines while also approaching development from multiple levels. The multilevel nature of developmental psychopathology is particularly important for addressing how early stress affects development because effects can occur on multiple levels, including, but not limited to, genetics/epigenetics, stress physiology, immune functioning, neural activity, cognition, emotion, behavior, social networks (e.g., family, peers, teachers), community, culture, and even at national and international levels in the form of public and global policy. An important aspect of the multilevel nature of developmental psychopathology is the recognition that bidirectional and transactional processes occur between each of these different levels (Cicchetti \& Dawson, 2002), such that social networks can influence neural activity and emotion just as neural activity and emotion can influence our social behavior and networks. Functioning at each of these levels does not operate in isolation, and it is vital to recognize how operations at each of these levels may be interacting at different points in time and development to shape observable phenotypes.

Another important consideration in the developmental psychopathology framework is the heterogeneity in developmental outcomes despite similar early experiences. For example, two children may have similar maltreatment experiences 
during early childhood, yet one of them is struggling with psychopathology as an adult while one is adapting well despite his or her early experience. These vastly different adult phenotypes resulting from the same early experience are examples of multifinality, with different pathways leading to different end states despite a shared initial early state (Cicchetti \& Rogosch, 1996). On the other hand, two adults with vastly different childhood circumstances might both develop depression, although their developmental pathways to the disorder are dissimilar. This is an example of equifinality, the concept that different initial states and processes can lead to the same end state (Cicchetti \& Rogosch, 1996). Multifinality and equifinality are particularly important to consider when creating and delivering interventions for those who are suffering adverse consequences following the experience of childhood stress, as children who have experienced maltreatment can respond to the stressor or an intervention in distinct ways that will likely have implications for their risk for future psychopathology. Likewise, pathways to outcomes such as depression and behavior problems are diverse, and as a result, prevention and intervention efforts may be more effective if these diverse pathways are taken into account.

The developmental psychopathology framework is helpful for understanding phenomena such as developmental cascades, which refer to effects that spread across multiple levels (micro to macro), across multiple domains (e.g., peer vs. family functioning), or across systems (e.g., within an individual, in a family system, in a community; Masten \& Cicchetti, 2010). An example of a developmental cascade that has been widely replicated is the cascade from early conduct problems to later internalizing and externalizing problems, health risk, and poorer school performance (Herrenkohl et 
al., 2010; Masten et al., 2005). Thus, problems in one domain can cascade to multiple domains, suggesting that an early risk factor may initially influence a single domain but alters the course of development more broadly over time. Developmental cascades may explain why early problems following childhood stress can cascade to problems at multiple levels and across domains in adolescence and adulthood. Cascading effects can be direct or indirect through a number of pathways, and they may be either adaptive or maladaptive. However, it is important to note that cascades are not deterministic; not all early problems spread to other domains, and there is great variability between individuals in the characteristics of cascades. Developmental cascades are particularly important for creating interventions, as well-timed interventions directed at specific targets may halt maladaptive cascades or promote adaptive cascades (Masten \& Cicchetti, 2010). Interventions that attempt to disrupt maladaptive cascades are central to developmental psychopathology, as interventions that change mediators between a stressor and a negative outcome and successfully disrupt a pathway to the negative outcome inform our understanding of developmental processes. For example, toddler-parent psychotherapy has been shown to reorganize attachment between mothers with depression and their toddlers (Toth, Rogosch, Manly, \& Cicchetti, 2006), which could disrupt known developmental cascades between attachment insecurity and internalizing and externalizing problems (Fearon, Bakermans-Kranenburg, Van IJzendoorn, Lapsley, \& Roisman, 2010; Groh, Roisman, van IJzendoorn, Bakermans-Kranenburg, \& Fearon, 2012).

The study of developmental psychopathology is enhanced by examining normal and abnormal development together. Conceptualizing psychopathology as a 
developmental deviation allows us to both outline the principles of normal development and to understand where normative processes can go awry (Sroufe, 1990). Certainly, in the context of stress exposure in childhood, these early processes that lead certain individuals to proceed in an adaptive manner versus deviating to developing psychopathology are vitally important. Abnormal developmental processes during stages of rapid neurodevelopment shed a light on how normal development should proceed during early sensitive periods and what processes are absolutely necessary for normal development. Likewise, investigations of both risk and resilience must be studied together, because it is likely that certain processes that increase risk for certain disorders are occurring at the same time as processes that are protective. In addition, identifying risk factors may help us to determine protective factors, and vice versa. For example, the knowledge that unpredictability in the early environment is a risk factor for later psychopathology points researchers to investigate whether early environmental stability serves as a protective factor that may be incorporated into interventions (Doom, VanZomeren-Dohm, \& Simpson, 2016; Simpson, Griskevicius, Kuo, Sung, \& Collins, 2012).

It is necessary to consider the complexity of development because individuals are rarely faced with only risk or protective factors. Indeed, there is an ongoing interplay between risk and protective factors in each individual that can change the probability of adaptation versus maladaptation in individual domains following early stress. Genetic, physiological, social, environmental, nutritional, and cultural processes, among others, may interact with each other over time to push the system toward maladaptation or adaptation. For example, an individual may have a genetic propensity toward 
schizophrenia and have grown up in poverty, which would confer risk for the onset of schizophrenia, yet also have a supportive social network and stable employment, which serve as protective factors. No individual factor determines whether this individual will develop schizophrenia, but these factors are likely to interact with each other and other contextual factors over time to shape his or her risk for psychopathology. Thus, the complexity of understanding multiple risk and resilience pathways is a central theme of the developmental psychopathology perspective.

Importantly, developmental psychopathology is sensitive to context, with the recognition that what is adaptive in one context may be maladaptive in another. For example, childhood stress has been associated with perturbations in threat-related attention biases (Pine et al., 2005). Altered attention to threat has been associated with anxiety symptoms and disorders and is thus maladaptive (Mogg \& Bradley, 1998), particularly if one lives in a low-threat context. However, changes in vigilance in a highly threatening environment might be adaptive, particularly if vigilance is increased, as the ability to detect threats may allow one to act quickly in a way that could preserve one's life or safety. Thus, it is essential to consider adaptations to early stress relative to the current context, as intervening to change a behavior that is adaptive for the current context may lead to negative outcomes for the individuals. An understanding of the immediate social and structural environment, culture, and global environment may be important for creating interventions that promote adaptive behaviors within specific contexts.

Central to developmental psychopathology is the principle of developmental plasticity, which is the ability of the brain and other physiological systems to reorganize 
and adapt to ongoing experiences throughout the life course. Plasticity is essential to adapt to current environments and to prepare for future environments. According to evolutionary theories, current experiences change functioning on multiple levels, which guides the path of development to expect a future environment that is similar to the current or past environment. Thus, any changes made to adapt to the environment are theoretically beneficial as long as the future environment matches the current or past environment. However, development may become abnormal if these processes go awry. Plasticity is necessary in order to shape development by responding to ongoing experiences and challenges. Neural plasticity from the molecular to the systemic level is essential for normal development and also contributes to aberrations in development (Cicchetti \& Walker, 2003; Cowell, Cicchetti, Rogosch, \& Toth, 2015; Van Praag, Kempermann, \& Gage, 2000). Biological factors impact psychosocial processes, just as psychosocial experiences affect gene expression and subsequent brain development and functioning (Cicchetti \& Tucker, 1994; Kandel, 1998; Kolb \& Whishaw, 1998). Importantly, neural plasticity does not remain stable throughout the life span, as experiences that occur during rapid periods of neurodevelopment are more likely to have lasting effects on functioning (Knudsen, 2004). The prenatal and early postnatal years in humans are associated with the greatest neuroplasticity, and thus, stressful experiences that occur early in life are thought to be particularly important for shaping neurodevelopment (Shonkoff et al., 2012; ; Teicher et al., 2003). Theories and Models Informing the Role of Stress in Developmental Psychopathology 
To describe research on how childhood stress shapes later adaptation, it is important to highlight a few theories and models that have guided research in the field or have utilized the developmental psychopathology framework. Thus, we will briefly discuss the organizational-developmental perspective, developmental systems theory, the allostatic load model, and the adaptive calibration model in relation to developmental psychopathology.

The organizational perspective of development argues that developmental outcomes are shaped by interactions between biological, genetic, psychological, and sociological variables within specific environmental contexts Cicchetti \& SchneiderRosen, 1986; Egeland, Carlson, \& Sroufe, 1993; Sroufe, 1979). Any of these variables may serve as risk or protective factors, and these variables interact in transactional processes over time. The individual is an active participant in development, whereby his or her feelings, expectations, and attitudes guide interpretations of new experiences, such as a stressful event, and organize future behavior based on these interpretations. Patterns of behavior are not static in the context of stress and may change over time. Thus, competence at one particular time point does not ensure later competence, but rather prepares an individual for competence in the next developmental stage. Severe stressors during childhood can negatively influence competence, which may or may not impact competence at later developmental stages depending on risk and resilience processes unfolding over time. The organizational perspective is essential for informing developmental psychopathology's focus on multiple levels of functioning across development and understanding how risk and protective factors interact over time. 
Developmental systems theory examines how individuals carry out transactions with their environments and how these transactions affect biology, genetics, behavior, and the environment of the individual across development (Ford \& Lerner, 1992). Thus, development is the result of many interacting systems that must be understood within one's ecological context, or as a dynamic cascade of many of these transactional processes happening over time (Cox, Mills-Koonce, Propper, \& Gariépy, 2010). Over time, these processes lead to behavior patterns through self-organization that emerges from the interactions of these systems. Developmental systems theory informs developmental psychopathology through delineating the transactional nature of multilevel interactions between the individual, biology, and the environment across time.

The allostatic load model (McEwen, 1998; McEwen \& Seeman, 1999) revolves around the concept of allostasis, which refers to an organism maintaining stability by constantly adapting to changes in the environment. Allostatic load refers to wear and tear on the body due to repeated cycles of allostasis, particularly if biological systems have difficulty with efficient activation or cessation following environmental challenges (McEwen \& Seeman, 1999). For example, repeated activation of cardiovascular, neuroendocrine, immune, or metabolic systems in response to challenge may lead to damage resulting from these mediators that have negative implications for mental and physical health (Juster, McEwen, \& Lupien, 2010). The allostatic load model takes into account perceived stress, physiological and behavioral responses to stress, and individual differences in responses, which are important determinants of allostasis and allostatic load (McEwen \& Seeman, 1999). The allostatic load model is informative for 
considering how adaptations made in response to stress could lead to negative consequences for multiple biological systems and behavior.

The adaptive calibration model is an evolutionary-developmental theory on the origin of individuals differences in stress response systems (Del Giudice, Ellis, \& Shirtcliff, 2011), which is an extension of the biological sensitivity to context theory (Boyce \& Ellis, 2005). Unlike the allostatic load model, the adaptive calibration model frames adaptations to the environment as part of an organism's life history strategy, which biologically organizes one's developmental trajectory and how resources are allocated in order to improve evolutionary fitness via activities such as mating and parenting. The adaptive calibration model also argues that there are differences in sensitivity to the environment and experiences that can lead to individual differences in responses to certain environments. For example, an individual who is more biologically sensitive to the environment may gain greater benefits from a positive environment and suffer greater harm from a negative environment than someone who is less biologically sensitive to the environment. Across the life span, information about the environment is encoded in order to feed back onto the stress system's calibration. The evolutionary nature of this theory is particularly apparent when arguing that organisms have evolved to be able to modify their developmental trajectory to match the current environment in order to enhance the chances of successful adaptation. This model is important for developmental psychopathology in understanding multilevel effects of childhood stress across development while also providing a framework for understanding possible reasons behind the phenomena of multifinality and equifinality. 


\section{Types of Stress Exposure Within the Developmental}

\section{Psychopathology Framework}

Childhood stress is often broadly construed, ranging from social stressors such as maltreatment or harsh parenting, to environmental stressors like living in poverty or a dangerous neighborhood, to physical stressors such as poor nutrition, health problems, or toxin exposure. These stressors may be acute, such as the death of a parent, or chronic, such as living in an institution or foster care for long periods of time. In addition, stressors can range from mild to toxic in severity, with the toxic stressors associated with the highest risk for mental and physical health problems across development, even though there is variability in which stressors may be toxic for certain individuals (Shonkoff et al., 2012). Measuring and conceptualizing childhood stress for the purposes of integrating it in research and interventions poses several challenges. First, young children may not always be reliable reporters of stressful experiences, and children may not be aware of family-level stressors that nevertheless impact the child through changes in caregiving or in the environment. Retrospective reporting of childhood stress is also subject to problems with accurate recall (Hardt \& Rutter, 2004; Maughan \& Rutter, 1997). Second, there is a long-standing debate regarding whether to measure objective stressors or one's subjective response to the stressor. Third, some researchers argue that it is best to measure stress as a composite of all negative experiences in childhood, while others argue that specific stressors may have unique effects on development and should be studied separately. Similarly, there is a problem with nonindependence of stressors, meaning that individuals who experience a stressor like poverty will be more likely to experience other types of stressors, like malnutrition, maltreatment, and neighborhood 
violence. Thus, it is challenging to identify unique effects of specific stressors. Although we will not resolve these issues in this chapter, we believe it is important to remember these points while considering the effects of different stressful experiences in childhood on development. We now review a nonexhaustive list of childhood stressors that have been examined through a developmental psychopathology lens and discuss how these stressors heighten risk for maladaptive development.

\section{Maltreatment}

A large body of literature has documented the impacts of child maltreatment, such as neglect, emotional abuse, physical abuse, and/or sexual abuse, on neurobiological, socioemotional, cognitive, and behavioral functioning across the life span (Cicchetti \& Valentino, 2006). Extensive research shows that child maltreatment increases the likelihood of disruptions in developmental processes and downward effects on multiple levels of functioning, including neurobiology, cognition, emotion, behavior, and social functioning (Cicchetti \& Toth, 1995; De Bellis, 2001; Masten \& Cicchetti, 2010). Specifically, alterations in physiological responsiveness, emotion understanding, attachment, social information processing, academic achievement, peer and romantic relationships, attention, and neural processes have been related to the experience of child maltreatment (Cicchetti \& Valentino, 2006; De Bellis, 2001). These alterations place children who have experienced maltreatment at significant risk for problems such as substance abuse and psychopathology throughout the life span (Cicchetti \& Valentino, 2006). Adding to the stress of maltreatment, children who have been maltreated are more often from homes characterized by low socioeconomic status (Sedlak et al., 2010), and 
they have therefore typically been exposed to stressors associated with poverty in addition to maltreatment.

However, not every child who has been maltreated is doomed to a future of psychopathology or poor functioning on multiple levels. Many maltreated children do remarkably well despite this traumatic early experience, and researchers have focused on these children to understand what factors promote positive adaptation, or resilience, following maltreatment (Cicchetti, 2013; Masten, 2001). Resilience is an ongoing process influenced by multiple individual, social, environmental, and cultural factors, so adaptations made in several domains can be adaptive at one time point and maladaptive later, or vice versa. Overall, there is evidence that ego resiliency, positive self-esteem, active coping, quality friendships, and a consistent supportive relationship with at least one adult are protective factors related to a higher likelihood of adaptive functioning (Cicchetti, 2013). Genetic, neurobiological, and physiological factors also play a role in resilience processes (Cicchetti, 2013). We can use these insights to create interventions that promote resilient functioning in children who have experienced maltreatment.

\section{Institutional Deprivation}

A significant literature on neglect focuses on children's experience of early social deprivation due to institutional (e.g., orphanage) care. Though the quality of institutional settings varies widely, these are typically marked by some degree of social and stimulus deprivation for infants and children. This involves fewer social interactions with caregivers, instability of caregivers, and less quality interaction with the environment. Children who have experienced significant periods of institutional care, even after placement in stable families, show aberrant interpersonal behavior, including 
indiscriminate friendliness and a higher likelihood for insecure attachment (Bruce, Tarullo, \& Gunnar, 2009; Chisholm, 1998), and they are more likely to have emotional difficulties and internalizing and externalizing problems (Colvert et al., 2008; Zeanah et al., 2009). Recent research suggests that early alterations in cognitive control and visual attentional biases may cascade to predict later psychiatric symptoms (Troller-Renfree, Zeanah, Nelson, \& Fox, 2017). In addition, early alterations in emotion recognition may precede psychiatric problems as well (Fries \& Pollak, 2004). Overall, for many domains, the longer the child spends in institutional care, the more severe the alterations in functioning tend to be, but there is typically a great deal of recovery for children who are adopted out of these environments into homes with stable, supportive caregivers (Doom \& Gunnar, 2016).

\section{Harsh Parenting}

Harsh parenting, or care that is aversive to the child but less so than maltreatment, refers to a punitive parenting style characterized by spanking, being overly negative, and threatening or yelling at the child. Harsh parenting has been associated with increased risk for behavior problems that can have lasting effects on multiple domains, particularly child aggression (L. Chang, Schwartz, Dodge, \& McBride-Chang, 2003). One study demonstrated that child emotion regulation mediates the association between harsh parenting and child aggression, indicating potential emotional and cognitive effects that are more proximal in timing to the exposure to harsh parenting (L. Chang et al., 2003). Interestingly, harsh parenting from mothers was more associated with impaired child emotion regulation, whereas harsh parenting from fathers was more strongly associated 
with child aggression, suggesting that the impact of harsh parenting differs depending on the parent (L. Chang et al., 2003).

\section{Poverty}

Children growing up in poverty have higher rates of anxiety and attention problems, depression, and conduct disorders (Hackman, Farah, \& Meaney, 2010). These children are more likely to have subclinical levels of internalizing and externalizing problems, lower intelligence, and poorer academic achievement, with a greater duration of poverty linked to greater risk for negative outcomes (Hackman et al., 2010). Of course, poverty is complex. It does not solely indicate low education or income, but it can also encompass a wide range of stressors that are more commonly experienced by children living in poverty, including household stress and chaos, neighborhood violence, parental psychopathology, disruptions in parenting and relationships, fewer community supports, poor nutrition, and environmental contaminants, among others (Evans \& English, 2002). It is difficult to empirically determine what aspects of poverty provide the greatest risk to children, but it is likely that many of these poverty-associated factors interact over time to influence risk and resilience processes.

Research on the effects of child poverty on life-span development and the positive effects of early intervention have repeatedly stated that investments in high-quality interventions early in life have the greatest impact on lifetime outcomes and the highest return on investment (Heckman, 2006). Thus, any interventions to reduce poverty or the effects of poverty on development will be the most effective during sensitive early periods of development in order to promote positive developmental cascades of outcomes across multiple levels. 


\section{Family and Community Violence}

Witnessing violence in the home can have a profound effect on children's socioemotional development, behavior, and risk for psychopathology. A meta-analysis indicated that exposure to domestic violence was associated with greater child emotional and behavioral problems; witnessing domestic violence increased problems in children who had suffered abuse themselves (Wolfe, Crooks, Lee, McIntyre-Smith, \& Jaffe, 2003). A separate meta-analysis indicated that being exposed to multiple forms of violence was more highly associated with behavior problems in childhood than one form of violence and that risk was similar for those who witnessed interparental violence and those who were victims of violence themselves (Sternberg, Baradaran, Abbott, Lamb, \& Guterman, 2006).

Witnessing violence in the neighborhood or community also increases risk for psychopathology. Children witnessing violence in the community or seeing a gun or drugs at home report higher levels of distress (Martinez \& Richters, 1993), and youth who witness community violence have higher rates of posttraumatic stress disorder (PTSD), depression, aggression, and externalizing behaviors (Buka, Stichick, Birdthistle, \& Earls, 2001). African American and Latino boys living in disadvantaged neighborhoods who were exposed to community violence experienced greater increases in aggression over 1 year (Gorman-Smith \& Tolan, 1998). Positive family functioningeven in the context of high levels of community violence — has been shown to be a protective factor against youth perpetrating violence (Gorman-Smith, Henry, \& Tolan, 2004). 


\section{Natural and Humanmade Disasters}

Children who have experienced the trauma of a disaster, such as hurricanes, tsunamis, earthquakes, and large fires, are at an increased risk for developing posttraumatic stress disorder (PTSD), depression, anxiety disorders, and other types of acute stress reactions and adjustment problems (Kar, 2009). Children may be less equipped to cope with the stress of a disaster than adults, which could partially explain children's increased vulnerability to psychopathology and other impairments post disaster (Goldmann \& Galea, 2014). It is difficult to predict children's responses to disasters, but on average, risk for adjustment problems rises with the frequency, number, or intensity of exposure (Masten \& Narayan, 2012). However, there is a great deal of variation, with some individuals showing positive adaptation, or resilience, in response to a disaster while others show greater maladaptation than would be expected given their exposure, indicating vulnerability (Masten \& Narayan, 2012). Most effects of disaster exposure are short term, although these can have lasting effects. Children who experience the loss or injury of a loved one typically have greater negative effects than those who only sustained material losses (Masten \& Narayan, 2012). Of course, protective factors moderate outcomes following disasters. One of the most consistent findings in the disaster literature is the buffering effect of being close in proximity to parents and other attachment figures when disaster strikes (Masten \& Narayan, 2012). Other protective factors include self-efficacy, self-regulation, belief that there is meaning in life, religious beliefs, intelligence, and community supports (Masten, 2001; Masten \& Narayan, 2012). Developmental cascades of positive or negative adaptation should be tracked following 
the onset of a disaster, with attention to the multiple levels of functioning that can be affected by an acute stressor.

\section{Chaos and Unpredictability}

In addition to major negative life events, there has been increased focus on the role that chronic unpredictability plays in shaping neurodevelopment and lifetime risk for psychiatric disorders. Forms of chaos examined in the field include a lack of structure and routine, background noise and crowding, frequent moves and substandard housing, and a frenetic pace of life (Evans, Gonnella, Marcynyszyn, Gentile, \& Salpekar, 2005).

Chaos is more common in low-income families, and there is evidence that chaos mediates at least some of the association between poverty and disruptions in socioemotional development (Evans et al., 2005). Studies of unpredictability and chaos in childhood have demonstrated that in households with higher levels of chaos, children are more likely to have problems behaviors, particularly combined with low-quality parenting (Coldwell, Pike, \& Dunn, 2006). Further, another group found that household chaos during the first years of life predicted greater child conduct problems and callousunemotional behaviors, mediated by parenting behavior (Mills-Koonce et al., 2016). Early unpredictability has even shown associations with adolescent and adult outcomes. For example, greater unpredictability (e.g., changes in residence, cohabitation, and parental occupation) before 5 years has been associated with greater externalizing behaviors and substance use in adolescence, and greater externalizing/criminal behaviors and more sexual partners in adulthood (Doom et al., 2016; Simpson et al., 2012). However, later unpredictability (between 6-16 years) was not as powerful a predictor of these later behaviors as early unpredictability, indicating a possible sensitive period for 
the experience of unpredictability (Doom et al., 2016; Simpson et al., 2012). Early unpredictability and chaos may interfere with the child's belief that he or she is an effective agent with control over the environment, alter the development of selfregulation, and lead to interruptions while the child is engaging with his or her environment (Evans et al., 2005). Disruptions in these processes may not be advantageous for shaping adaptive functioning in more stable environments, but they may set up neural systems that are more able to function in chaotic future environments.

\section{Racial Discrimination}

There are many forms of discrimination that may have negative psychological consequences; we will focus on the racial discrimination literature. Experiences of racial discrimination have repeatedly been associated with poorer mental health in children (Priest et al., 2013). Racial discrimination may impact children directly or indirectly, such as through a caregiver's experience that increases stress on that individual, which then affects his or her health or behavior. One study of African American families demonstrated that mothers with greater perceptions of racial discrimination experienced a stronger cascade from poorer maternal psychological functioning to negative parenting behaviors (Murry, Brown, Brody, Cutrona, \& Simons, 2001). Thus, racial discrimination likely impacts children even without their direct or conscious experience of it.

Racial discrimination may be even more distressing for individuals who experience immigration-related stress, which has further implications for family stability and safety. Future research is needed to better measure perceived discrimination in younger children and to conduct these studies across more racial/ethnic groups (Pachter \& Garcia Coll, 2009). Interventions that aim to reduce racial discrimination or the impact 
of racial discrimination on health should be sensitive to culture and context in order to achieve the best outcomes for minority youth (Spencer, Noll, Stoltzfus, \& Harpalani, 2001).

\section{Nutritional Deficiencies}

Stressors not often considered in the stress and developmental psychopathology literatures are macronutrient and micronutrient deficiencies, which is unfortunate because psychosocial stressors can interfere with nutrient absorption and trafficking (Monk, Georgieff, \& Osterholm, 2013), leading to nutritional deficiencies. Thus, a nutritional deficiency may be an extra "hit" to development in the context of psychosocial or environmental stress or a potential mediating pathway by which stress influences development. Low energy intake and macronutrient deficiencies, such as low protein or fat intake, in childhood have been associated with altered brain development. Linear growth stunting, low weight-for-height in young children, and signs of macronutrient deficiencies have been related to less play and positive affect, and also to a lower likelihood of secure attachment compared to typically growing children (Gardner, Walker, Powell, \& Grantham-McGregor, 2003; Graves, 1978). These early issues can

lead to conduct and attention problems and poorer quality relationships (S. Chang, Walker, Grantham-McGregor, \& Powell, 2002; Galler \& Ramsey, 1989; Richardson, Birch, Grabie, \& Yoder, 1972). Childhood growth stunting has also been associated with greater depression and anxiety symptoms, lower self-esteem, and increased hyperactivity (Walker, Chang, Powell, Simonoff, \& Grantham-McGregor, 2007). 
Childhood micronutrient deficiencies have also been associated with alterations in neurodevelopment. For example, iron deficiency during infancy has been associated with poorer cognitive functioning, emotional difficulties, and behavior problems, with some impairments from this early deficiency apparent into adulthood (Lozoff et al., 2006). Recent work on iron deficiency has examined developmental cascades and pathways from early nutrition to later functioning. Adults who experienced chronic iron deficiency in infancy reported greater negative emotions and dissociation/detachment than adults who were iron sufficient in infancy, with behavior problems during adolescence mediating this pathway (Lozoff et al., 2013). In addition, early iron deficiency predicted poorer emotion regulation in childhood, which was then associated with more risky sexual behavior and alcohol use in adolescence (East et al., 2017). These literatures are important for researchers studying early stress and psychopathology to consider.

\section{Environmental Toxins}

Although rarely studied in the stress and developmental psychopathology literatures, environmental toxins may negatively impact neurodevelopment and have lasting effects on mental health. Lead is one of the best-understood toxins in relation to child brain development (Grigg, 2004). Children are especially sensitive to lead exposure because they absorb greater amounts of lead through the gastrointestinal tract and more lead gets into the brain (Grigg, 2004). In addition, sensitive periods of brain development early in life put children at risk for greater damage to rapidly developing neural systems. Greater lead levels in children have been associated with lower IQ and less adaptive classroom behavior (Needleman et al., 1979), which could promote developmental cascades to psychopathology and maladaptation across development. Interactions between 
psychosocial stressors and environmental toxins should be considered when studying pathways of risk and resilience across development. More efforts must also be implemented to reduce risk of preventable lead exposure (e.g., the Flint Michigan water crisis; Hanna-Attisha, LaChance, Sadler, \& Champney Schnepp, 2016) to improve mental health and adaptive functioning in children.

\section{Genetics, Stress, and Developmental Psychopathology}

Advancements in genetic and epigenetic methods and an increased interest in integrating genetic methods into psychopathology research have resulted in an explosion of research attempting to understand the relative contributions of genetics versus the environment, how genes interact with the environment, and how the environment can affect the epigenome. We know through twin and adoption studies that many types of psychopathology associated with childhood stress exposure are partly heritable Rhee \& Waldman, 2002; Sullivan, Neale, \& Kendler, 2000). We also know that there are independent effects of genotype and environment, suggesting both genetics and the environment predict risk for psychopathology, and the interaction of genotype and environment ( $\mathrm{G} \times \mathrm{E}$ interaction) may confer further risk. There is a great deal of research on stable genetic variation among individuals that impact developmental outcomes, including single-nucleotide polymorphisms (SNPs), which are sites on DNA where a single nucleotide may differ between individuals. Such genetic variation has been targeted as a moderator of experiences and may lead to multifinality in outcomes for individuals experiencing the same type of childhood stressor. The first report on geneenvironment interactions for psychiatric outcomes found that individuals with the lowactivity MAOA allele who also experienced maltreatment were at an increased risk for 
antisocial behavior (Caspi et al., 2002). Investigations into many different gene candidates have followed, including FKBP5, a gene that regulates glucocorticoid receptor sensitivity, which in the context of childhood maltreatment has been associated with greater risk for PTSD in adulthood (Binder, Bradley, Liu, et al., 2008). However, there have been concerns about the replicability of many G x E candidate gene studies.

Researchers have also considered how different genotypes might interact with each other and the environment to predict further risk (e.g., G x G x E interaction; (Cicchetti, Rogosch, \& Oshri, 2011). Others have utilized previous data on "risk alleles," or alleles that confer risk in interaction with stressful environments, to create polygenic risk scores that combine these alleles into a composite that indexes overall risk across genes. One study utilizing polygenic risk scores reported independent effects of both the polygenic risk score and childhood trauma on risk for adult depression, as well as an interaction indicating that polygenic risk score was a stronger predictor of depression in the context of child trauma (Peyrot et al., 2014). Understanding the interactions of genes with each other and the environment is a complex task, however, and the exact downstream mechanisms for the effects of the genome on multilevel functioning are not understood, but such work holds promise for identifying targets for understanding pathways from environmental risk to disorder.

With advancements in methodology and statistics, researchers have been able to capture the effects of not just one or a handful of SNPs, but the potential contributions across the entire genome. Genome-wide association studies (GWASs) have incorporated studies of the whole genome to identify potential genetic loci that are associated with observed traits, which capture genetic influences rather than $\mathrm{G}$ x E interactions. This 
data-driven approach has been used to identify novel genes that reach the threshold of significance that may play unexpected yet important roles in conferring risk for disorders in the face of childhood stress (Bogdan, Hyde, \& Hariri, 2013). Perhaps with improving statistical tools, it will be possible to understand how genome-wide patterns may interact with the environment, and childhood stress specifically, to affect risk and resilience across development.

More recently, epigenetic processes (changes to the genome that are functionally relevant but do not alter the nucleotide sequence, such as chemical modifications that change gene transcription; Zhang \& Meaney, 2010) have become of interest to researchers of early stress and developmental psychopathology. Modifications such as DNA methylation or histone modification can alter the accessibility of DNA and the structure of chromatin, which then change gene expression. These changes have been targeted as a pathway by which childhood stress is embedded to confer risk for disorder (see 2016 Development and Psychopathology special section, vol. 28[4 part 2]). There is optimism that by understanding potential "rules" that govern epigenetics and gene expression, researchers can develop interventions that change gene expression and activity of downstream mediators of risk and resilience to lead to more favorable outcomes (Szyf \& Bick, 2013).

A seminal study in the effect of early experience on the epigenome in rodents reported that pups of low-licking and low-grooming mothers had greater methylation of the glucocorticoid receptor promoter than pups of high-licking and high-grooming mothers, and these alterations lasted into adulthood (Weaver et al., 2004). Parallel findings have also been reported in humans. A study of children exposed to physical 
maltreatment showed that these children had greater methylation of exon 1 of the NR3CI glucocorticoid receptor promoter region than nonmaltreated children (Romens, McDonald, Svaren, \& Pollak, 2015). This gene is the same gene that was found to be hypermethylated in the hippocampi of adult suicide victims that had experienced child abuse (McGowan et al., 2009). These suicide victims who had experienced child abuse also demonstrated decreased levels of glucocorticoid receptor mRNA, signaling a possible downstream mediator of hypermethylation on psychiatric risk (McGowan et al., 2009). However, there is difficulty with establishing causality due to the long period of time since the abuse in childhood. Changes in epigenetic patterns have also been reported in response to maternal deprivation (Massart et al., 2016), institutional care (Esposito et al., 2016; Naumova et al., 2012, and maternal depression (Cicchetti, Hetzel, Rogosch, Handley, \& Toth, 2016). Further, epigenetic changes have repeatedly associated with psychiatric disorders such as depression, addiction, and schizophrenia (Tsankova, Renthal, Kumar, \& Nestler, 2007). There is evidence that these alterations are potentially reversible (Roth \& Sweatt, 2011; Weaver et al., 2004), suggesting that the epigenome remains plastic in postmitotic cells.

Another area of recent interest has been in the transgenerational inheritance of the effects of early stress, including effects on the epigenome or on parental behavior that could impact the next generation even if they never directly experienced the stressor. Altered BDNF DNA methylation has been reported in the offspring of females exposed to maltreatment in early life (Roth, Lubin, Funk, \& Sweatt, 2009), suggesting an epigenetic mechanism of transmitting risk across generations or preparing offspring for a harsh environment. It is unclear whether demethylation of targeted DNA molecules as a 
result of an intervention may result in this change in the offspring, potentially decreasing risk for later disorder.

\section{Timing of Early Stress and Implications for Developmental}

\section{Psychopathology}

Childhood stressors may lead to different effects on brain development and behavior depending on the developmental timing of the stressor. Depending on the neurobiological development of the individual experiencing the stressor, his or her sociocultural and environmental context, genetics, personal history with stress, among other factors, the timing of a stressor may produce vastly different outcomes. For example, seminal work by Hubel and Wiesel demonstrated that restricting visual input during an early sensitive period had long-lasting effects on vision that are not apparent if visual input is restricted after the system's early development (Hubel \& Wiesel, 1962). Although the visual system has a relatively short sensitive period early in life, many of the neural systems in humans have more protracted periods of development (Stiles \& Jernigan, 2010), leaving the brain vulnerable to insults but also open to experiences that enhance development. Likewise, these brain regions and neural circuits each have unique sensitive periods of development that may help to explain the effects of early stress on functioning (Teicher, Tomoda, \& Andersen, 2006). Interestingly, the duration of sensitive periods has been

shown to vary between individuals based on environmental inputs (Knudsen, 2004), such that there are individual differences with respect to when sensitive periods begin and end. In this section, we will discuss examples of the differential effects of stressor timing on development. Although this chapter is focused on childhood stress, we want to emphasize 
that stressors outside of this period, such as during prenatal development or during adolescence and beyond, have specific effects that must be considered when endeavoring to understand developmental psychopathology across the life span (see 2015 Development and Psychopathology special issue on sensitive periods, vol. 27, issue 2).

The adoption literature has shed light on early sensitive periods due to the welldefined removal from a sometimes depriving environment and placement in a typically well-resourced family that is highly committed to the child. Depending on the timing of adoption and time spent in an institution or other care arrangements, researchers have been able to determine which periods of development are associated with the greatest risk for later cognitive, social, emotional, and behavior problems. Overall, children adopted before 12 months of age have better outcomes than those adopted after 12 months (Juffer \& van IJzendoorn, 2009). One meta-analysis reported that children adopted before 12 months were just as likely to be securely attached as children who were living in their birth families (Van den Dries, Juffer, van IJzendoorn, \& Bakermans-Kranenburg, 2009), suggesting that the sensitive period for attachment may not end during the first year of life. However, children adopted after 12 months were less likely to be securely attached than their nonadopted peers (Van den Dries et al., 2009), indicating that there does appear to be a sensitive period for attachment and that it closes sometime after 12 months of age. Interestingly, growing evidence indicates that for most, but not all, domains of functioning, as long as institutional care is limited to the first 4-6 months of life, there is no significant increase in long-term adverse effects (Zeanah, Gunnar, McCall, Kreppner, \& Fox, 2011). Thus, for many domains of functioning, the sensitive period lasts beyond 4-6 months of age. 
Researchers are still trying to understand whether the effects of adversity during specific sensitive periods can be reversed or whether there are sensitive periods at different points in development that make reversal of effects more likely. At this point, there is evidence in the epigenetics literature that some of these effects of early stress can be reversed (Roth \& Sweatt, 2011; Weaver et al., 2004). While there is mounting evidence that early stressors such as caregiver abuse and separation from a caregiver are associated with stable alterations in DNA methylation and gene expression in the animal literature (discussed earlier in section on "Genetics, Stress, and Developmental Psychopathology"), there is also evidence that at least some of these effects may be modifiable following these early experiences (Roth \& Sweatt, 2011), which is an exciting prospect for future interventions seeking modifiable targets that may influence functioning.

The hypothalamic-pituitary-adrenal (HPA) axis, which assists with the coordination of the brain and body's response to stress, and epigenetic regulation of the HPA axis have shown sensitivity to stressor timing. A 3-hour daily separation of infant mice from caregivers during a sensitive period of development in infancy has been shown to trigger epigenetic modifications that change HPA activity (Murgatroyd et al., 2009). Specifically, this early stressor induced HPA hyperactivity in basal and stress-related conditions and altered memory and coping behavior (Murgatroyd et al., 2009). Similar timing effects on the HPA axis have been reported in humans. An examination of adolescents followed longitudinally in the TRAILS cohort showed that while adversities between ages 0 and 5 years were not associated with cortisol reactivity to social stress, adversities between ages 6 and 11 years were associated with heightened reactivity, 
particularly for those who had experienced pre- or postnatal adversity (Bosch et al., 2012). Conversely, adolescents who had experienced adversity between 12 and 13 or 14 and 15 years demonstrated cortisol hyporeactivity to stress (Bosch et al., 2012). It is unclear whether puberty may play a role in transitions from hyper- to hyporeactivity in response to stress.

Volumetric magnetic resonance imaging (MRI) and functional MRI (fMRI) studies have revealed timing differences in the effects of early stress on the brain, which is in line with work on typical brain development showing major developmental differences in the brain and neural circuitry from prenatal life to adulthood. Preliminary evidence suggests that adult women who experienced repeated episodes of sexual abuse in childhood had reduced hippocampal volume compared to healthy control women if the episodes occurred at preschool age (3-5 years) or early adolescence (11-13 years; (Andersen et al., 2008). If the episodes of abuse occurred during middle childhood (9-10 years), corpus callosum volume was reduced, and the frontal cortex was reduced for those with sexual abuse experienced between 14 and 16 years compared to controls (Andersen et al., 2008). Although these timing effects need to be replicated in a larger sample, and preferably a sample with objective reports of maltreatment, they provide important data concerning effects of maltreatment timing on the developing brain. A prospective longitudinal study demonstrated that at age 24 , adults from families with lower income at age 9 showed reduced dorsolateral and ventrolateral cortex activity and failed to inhibit amygdala activation during a task requiring regulation of negative emotion (Kim et al., 2013). In this study, concurrent adult income was not associated with neural activation during the task, suggesting that the middle childhood environment 
had stronger programming effects than the current environment. Additionally, experiencing chronic stress across childhood and adolescence (at 9, 13, and 17 years) mediated the association between age 9 income and dorsolateral and ventrolateral cortex activity at 24 (Kim et al., 2013), suggesting that chronic stress exposure starting in childhood may be a mechanism by which these stressful experiences are programmed in the brain.

It is also unknown whether certain systems exhibit greater plasticity than others (Cicchetti, 2015), responding more to both positive inputs, such as stable, sensitive relationships, and negative inputs, such as chronic stress. Although we are gathering more data about the duration of sensitive periods across different systems, we have many questions to answer about the potential beginnings and endings of sensitive periods, the peak of plasticity during sensitive periods, and potential reemergence of sensitive periods at key points in development. These questions are especially difficult to answer when considering sensitive periods for complex behaviors and skills, such as executive function and social behavior, and phenotypes such as depression, schizophrenia, or conduct disorder. Such insights will be particularly important when creating evidence-based, developmentally sensitive interventions.

Another consideration relevant to timing is the possibility for childhood stress exposure to lead to sleeper effects months or years later. Sleeper effects are not immediately observed but may emerge at a later point. These are likely due to underlying vulnerabilities as a result of the stressor that may worsen and become more apparent across development when relevant systems are challenged. An example from the adoption literature is that children adopted from the less severely depriving orphanages 
did not show clinical- or borderline-level problems until around 12 years of age or older (Merz \& McCall, 2010). These reports suggest that the effects of institutional care are not solely due to immediate behaviors that help children adapt to orphanage care but are maladaptive in a family setting (Zeanah et al., 2011). Institutional care may disrupt more basic processes that become more apparent when relevant tasks emerge later in development, such as during adolescence (Zeanah et al., 2011). Thus, the timing of potential downstream effects must be considered in addition to the timing of the stressor.

The question of timing is particularly important in the intervention literature, as interventions that occur during a period of high plasticity for the intervention target are more likely to have effects. Much of the literature on childhood poverty and other stressors highlights the importance of intervening as early as possible while the brain is experiencing rapid development (Doyle, Harmon, Heckman, \& Tremblay, 2009). Programs intended to ameliorate the effects of early poverty and stress that occur during childhood are more likely to have a positive impact on developmental outcomes than interventions that occur during adolescence and adulthood because the brain has greater plasticity during the early years (Doyle et al., 2009). Interventions that begin even earlier, such as in infancy or even prenatally, might have even greater potential for positive developmental cascades. It is important to note that even though early interventions are often considered to be the most effective for producing change, interventions that are appropriately timed to intervene during a sensitive period of development may be even more effective than an earlier time point that is not a sensitive period. For example, an intervention to improve peer relationships or reduce delinquency and substance use may be better suited for late childhood or early adolescence than infancy. Questions of timing 
should always be considered in light of the developmental science literature. Likewise, the developmental literature must be informed by the timing of interventions that successfully change the behavior or outcome of interest, because this change could signal that there is malleability in that trait at the time the intervention was delivered. One example is the Bucharest Early Intervention Project in which children living in an orphanage were placed into foster care at various points in early development. A followup of these children at age 8 years demonstrated that children who were placed into foster care before 2 years of age had similar brain electrical activity to a never-institutionalized group, but those who were placed into foster care after 24 months showed significant differences in electrical activity compared to both of these groups, suggesting a sensitive period for early intervention in this domain (Vanderwert, Marshall, Nelson III, Zeanah, \& Fox, 2010). Basic and intervention scientists must embrace cross-talk between the literatures to advance both basic science and interventions.

\section{Stress, Adaptation, and Maladaptation}

Children's responses to stress must be considered in context to assess adaptation versus maladaptation. A child who develops behavior problems following maltreatment may struggle in a classroom where disruptive behaviors are not tolerated; thus, these behaviors would be maladaptive for functioning in the classroom. These same behaviors may serve a protective role in that other children may be weary of getting into fights with this child, which protects the child from certain peer conflicts. These behaviors may also help the child get attention and social interaction from teachers and other adults that he or she is not getting at home, which may be an adaptive response to a pathological environment. Thus, when considering negative behaviors or other outcomes following severe 
childhood stress, it is paramount to consider how this behavior might be functioning to help the child adapt, even if it is not adaptive in all contexts. The importance of considering both adaptations and the environment in research on developmental psychopathology and interventions for children who have experienced early stress cannot be overstated.

Researchers often think about the stress literature using a deficit model, which only highlights negative effects of stress. While acknowledging the significant deficits that often result for many children, it is important to consider the unique strengths and abilities that children who have experienced chronic stress may have that can help them adapt in certain contexts (Ellis, Bianchi, Griskevicius, \& Frankenhuis, 2017). Recent work has supported specialization and sensitization hypotheses (Ellis et al., 2017), which, within the evolutionary-developmental framework, argues that harsh, unpredictable environments enhance certain cognitive abilities in order to solve problems in these same environments (Frankenhuis \& de Weerth, 2013). One example is that the ability to shift attention in harsh, unpredictable environments may enhance adaptation to take advantage of fleeting opportunities, even though sustained attention abilities may be impaired (Mittal, Griskevicius, Simpson, Sung, \& Young, 2015). The sensitization hypothesis argues relatedly that these enhanced cognitive capabilities will be specific to conditions of stress and uncertainty rather than in nonthreatening circumstances (Mittal et al., 2015). A better understanding of these enhanced abilities will be necessary for designing interventions that take advantage of these abilities to increase intervention effectiveness and improve functioning in a variety of settings. 
An example of this effect of early experience comes from a study comparing youth who had a history of previous institutionalization to those who did not. In an experimental paradigm designed to test exploration versus exploitation strategies, formerly institutionalized youth were less likely to explore and more likely to exploit immediate rewards (Humphreys et al., 2015). The exploitation strategy was associated with greater success in a restricted task condition compared to a generous task condition. Thus, this history of early stress was associated with a strategy that favored a greater likelihood of success only in a condition of restriction, which likely matches an early environment where there is little control over future rewards. This behavior may be adaptive in unpredictable environments but maladaptive in stable, predictable environments.

Similarly, environmental mismatch (Nederhof \& Schmidt, 2012) refers to maladaptive outcomes that may occur when the current environment does not match the environment for which one has been behaviorally and biologically prepared. For example, if an individual's behavior and physiology has been programmed to be successful in a harsh early environment, the individual may experience difficulties if he or she ultimately lives in an environment of stability with many resources in adulthood. The individual may have been programmed to be vigilant to threat in early life, but this may not be adaptive in a low-risk environment and may lead to issues with attention or anxiety. It is possible that some individuals are more sensitive to the effects of early experience and thus have more difficulty adjusting to a change in the environment than others who were less sensitive to the environment (Nederhof \& Schmidt, 2012). A better understanding of sensitivity to the environment and environmental mismatch may help us 
to understand resilience and successful versus unsuccessful adaptations to different environments following early stress. The environmental mismatch hypothesis is particularly interesting for individuals in the development psychopathology field because this hypothesis considers the timing of exposures, developmental processes, and individual differences that may affect multiple levels of functioning. Thinking about environmental mismatch leads us to the question of whether interventions designed to promote behaviors that are more likely in children from low-risk backgrounds would be adaptive for children from high-risk backgrounds, particularly in contexts with the greatest levels of risk (e.g., in a dangerous neighborhood or with a maltreating caregiver). We must also ask whether such interventions designed to promote resilience work with or work against the adaptations children have already made to their high-risk environments (Ellis et al., 2017). We must strive to promote positive outcomes without taking away the certain skills necessary to survive in that environment.

The concept of resilience is essential to discuss when considering positive outcomes despite the experience of childhood stress. Although childhood stress has been associated with a greater likelihood of cognitive, socioemotional, and behavior problems, some who experience such adversity later excel in multiple domains. Resilience is a process that includes positive adaptation in the context of significant stress (Luthar, Cicchetti, \& Becker, 2000). Resilience is a dynamic developmental process, which indicates that it has the capacity to change over time in response to the environment and is greatly influenced by individual factors (Egeland et al., 1993; Luthar et al., 2000). Researchers have identified many factors that promote resilience processes, including individual factors such as intelligence and self-control, relationship factors such as 
sensitive, reliable parenting, and systems-level factors such as community support and effective schools (Masten, 2001, 2014). These factors support basic processes that allow individuals to flexibly adapt to their environment while supporting the development of psychological and physiological systems that are needed for successful adaptation to future environments. These factors, and others that support resilience processes, have been referred to as "ordinary magic" because they utilize normal human resources in children, families, and communities but have powerful effects on promoting resilience (Masten, 2001). A limitation of this literature is that it is difficult to differentiate between factors that decrease risk versus factors that promote resilience. A better understanding of the incremental contribution of resilience factors will be important for interventions that seek to promote specific resilience factors in addition to decreasing risk factors. It is important to remember, though, that some factors associated with resilience may not be adaptive in every context. Coping, a process that is often discussed in the resilience and developmental psychopathology literatures, can be adaptive or maladaptive depending on the type of coping used, the environmental context, and the characteristics of the individual (Compas, Orosan, \& Grant, 1993; Zeidner \& Saklofske, 1996). It is important to recognize that adaptive coping can occur even in the context of psychopathology (Cicchetti, 2010; Masten, 2014), so there is a great deal of variation in risk and protective factors interacting at a particular time. As a result, there is a need to understand both adaptive and maladaptive processes and recognize that these processes may be occurring at the same time in an individual.

\section{Sex Differences}


Sex differences in psychopathology, mechanisms that lead to psychopathology, vulnerability to stress, and resilience processes have been a growing focus in the developmental psychopathology literature. Simultaneously, the National Institutes of Health have required researchers to include participants of both sexes to be able to examine biological sex as a variable that might moderate the processes we are studying. Although sex differences in the prevalence of disorders may be well studied, there is less of a focus on sex differences in vulnerability to stress at different time points, how moderators impact risk for disorders, and the mechanisms that contribute to risk and resilience. We will attempt to highlight examples of research that incorporates sex differences in the study of childhood stress and developmental psychopathology.

One of the most prominent sex differences in the developmental psychopathology literature is that for depression. Depression is twice as likely to afflict females versus males (Nolen-Hoeksema, 2001), and this sex difference appears around the time of puberty. Careful developmental work has elucidated that sex differences in the prevalence of depression begin to emerge at 13-15 years of age, but the peak rate of divergence between the sexes is between 15 and 18 years (Hankin et al., 1998). Thus, this period during late adolescence may be a crucial point to intervene to reduce depression, particularly for females. Biological, socioemotional, cognitive, and behavioral differences between males and females during this period should also be targeted to understand what causes this substantial sex difference in depression. Interventions that reduce sex differences in depression during this period will help us to understand causality by experimentally determining which targets the intervention successfully altered to reduce depressive symptoms. 
Sex differences in response to stress have been observed in several domains, and these sex differences could contribute to known disparities in certain health problems, such as depression, conduct disorder, autoimmune disorders, and cardiovascular disease. For example, boys with more pervasive maltreatment (i.e., chronic, severe, multiple types of maltreatment) demonstrated greater diurnal cortisol levels in middle childhood than girls with similar maltreatment experiences (Doom, Cicchetti, Rogosch, \& Dackis, 2013). Similarly, girls with early but not recent maltreatment experiences and girls with more pervasive maltreatment experiences showed diurnal cortisol production consistent with down-regulation across development (Doom et al., 2013). These patterns may predispose males and females to different disorders as early as childhood, and these early differences suggest that biological sex is a critically important variable to consider even before the onset of puberty.

Genetic variants may also differentially operate to increase vulnerability or protection from the effects of trauma for boys versus girls. The corticotropin-releasing hormone receptor 1 (CRHR1) A-allele appears to protect males who experienced childhood trauma — but not females - from developing depression in adulthood, and this variant also predicts differential response to the dexamethasone/corticotropin-releasing hormone (CRH) test for males only (Heim et al., 2009). This test has been associated with HPA dysregulation and risk for depression. Sex differences in protection from the effects of trauma by genotype are an important avenue for researchers to explore to continue to elucidate disparities in psychopathology by sex.

Extensive research shows that children who experienced maltreatment are at an increased risk for affective disorders, and for females, trauma during the rapid period of 
brain development in early childhood is the highest predictor for lifetime risk of affective disorders (Bale \& Epperson, 2015). There are numerous differences in brain architecture and hormonal milieu by sex during typical development, and traumatic early experiences have been shown to alter brain development in a sex-specific manner (De Bellis \& Keshavan, 2003; Teicher et al., 2003). These divergences at baseline and in response to childhood stress must be more closely studied in order to understand risk for maladaptation.

In response to witnessing or being the victim of violence, studies have reported that girls have more serious symptomology, such as anger, anxiety, depression, and posttraumatic stress, than boys (Gorman-Smith \& Tolan, 2003). Girls may display more psychological distress in response to violence exposure while boys may display more risky behaviors (Gorman-Smith \& Tolan, 2003). The disaster literature has documented similar sex differences in response to stress, with girls showing greater anxiety symptoms and boys displaying more "belligerence" (Masten \& Narayan, 2012). One of the most consistent sex differences in response to stress is that females who are exposed to disasters, terrorism, or war in childhood or adolescence report greater posttraumatic stress symptoms than males (Masten \& Narayan, 2012). Males have been shown to be more susceptible to substance use disorders than females following trauma Goldmann \& Galea, 2014). However, it is difficult to disentangle biological sex from differences in males and females' exposure to stress, interpretations of stress, and self-report of the stressors and psychological/behavioral symptoms (Masten \& Narayan, 2012). Future work must consider these potential contributors to sex differences in response to trauma in order to create more fine-grained interventions following childhood stress. 
Future work must consider how pathways to mental and physical health problems following early stress may differ by sex. Data from the Midlife Development in the United States (MIDUS) survey suggested that childhood trauma was associated with an increased risk for metabolic syndrome in adulthood for both men and women, partially mediated by the pathway of poor-quality sleep (Lee, Tsenkova, \& Carr, 2014). For women only, stress-induced eating partially mediated this pathway, suggesting that this target may be specific to interventions in females (Lee et al., 2014). In addition, intervention effectiveness must be tested by sex to ensure that both males and females derive benefits from interventions. If only one sex benefits from an intervention, in-depth analysis is needed to understand why.

\section{Future Directions in Developmental Psychopathology}

Although much progress has been made in the understanding of developmental pathways between childhood stress, psychopathology, and resilience, there are still many questions that must be answered. First, we need to better understand how the timing, type, and severity of stress during development affect outcomes. There is a great deal of heterogeneity in functioning between individuals. In addition, individuals may have adaptive functioning in some domains, such as social behavior and cognitive functioning, but not other domains, such as emotion regulation and stress system functioning. More careful phenotyping and gathering both objective and subjective measures of the environment and individuals' stress histories, if possible, will yield greater understanding into individual differences in functioning at multiple levels. Similarly, we need to understand what these individual differences mean for personalized interventions. There is an urgent need to adapt interventions for individuals based on type of stress, timing and 
chronicity of stressor, and age at the time of intervention in order to enhance prevention and intervention effectiveness. In light of processes related to environmental mismatch and adaptations made to stressful environments, it will be important for prevention and intervention scientists to consider how responses to stress may be adaptive to the current environment, and whether altering these responses may in turn decrease one's ability to function in a threatening environment. Although highly difficult to conduct, individualized interventions may be the most effective when paired with changes in the environment that complement cognitive, behavioral, socioemotional, and biological alterations targeted by the intervention. Interventions should also capitalize on unique strengths of children who have experienced early stress, such as enhancements in specific types of memory formation, heightened attention to different types of information, or performance on certain risk-taking tasks, in order to increase adherence and effectiveness (Ellis et al., 2017).

We have extensive evidence that childhood stress alters neurobiological systems, cognition, emotion, and behavior, but we still have much more to understand about specific neurobiological mechanisms that link early stress to these later outcomes. The best evidence for causal models and neurobiological pathways is in animal models. For example, researchers have documented epigenetic changes in response to maltreatment in mice, which are then linked to alterations in the HPA axis, cognition, and behavior (Murgatroyd et al., 2009). Although we cannot causally test these pathways or have highly controlled environments in humans, we should continue to assess multiple levels of functioning across time to test whether these pathways likely operate in humans. Because there are likely pathways operating at multiple levels that lead to biological and 
behavioral embedding of early experiences, we should investigate how these pathways interact over time to alter functioning. Genetics and epigenetics, neural activity and neurotransmitter systems, the autonomic nervous and immune systems, the HPA axis, the microbiome, and the environment, among a host of other factors interact over time to produce complex phenotypes. A greater understanding of these pathways and interactions will provide valuable targets for interventions that seek to promote adaptive functioning at multiple levels. In addition, future work in the $\mathrm{G} \times \mathrm{E}$, childhood stress, and psychopathology literatures is needed to understand the interaction between genetics and environmental contributions to risk and resilience. For example, passive geneenvironment correlations (rGE; e.g., parent and child share genes and parent also shapes environment for the child), active correlations (genetically influenced traits lead one to seek out particular environments), and evocative correlations (genetically influenced traits evoke environmental responses) may make stressful environments more likely for certain individuals. Thus, childhood stress may be partially due to both genetics and the environment, which is important to remember for prevention and intervention.

In the future, we must keep working on creating truly developmental theories that integrate psychological, genetic, physiological, environmental, and cultural processes that guide normal and abnormal development. There is a great need for research that integrates cultural development into developmental psychopathology, including the ways in which culture affects biology, incorporating assessment of individual- and societylevel cultural processes, and the best ways to integrate culture into interventions (Causadias, 2013). We must continue to refine our measures, study designs, and statistical approaches to analyze complex longitudinal data at multiple levels. We have 
made a great deal of progress in the past three decades on integrating biological measures into psychology research, and we should keep trying to mechanistically understand how psychological and biological processes interact across development. This effort includes implementing both psychological and biological measures pre and post intervention in order to understand the potential biological mechanisms that may significantly mediate intervention effectiveness. Finally, we must use interventions as a way to study causality of psychopathology in the face of stress. Although randomizing children to stressful conditions is not possible, we can randomize children to interventions. If children respond to these multilevel interventions, this provides evidence that these targeted systems are sensitive to the environment at that point in development (Cicchetti, 2013). Randomization to preventive interventions serves the same function for testing theories and pathways from stress to psychopathology (Howe, Reiss, \& Yuh, 2002). Such investigations will allow us to understand what is a causal agent in a disorder versus a byproduct of that disorder. These investigations will also inform us about the developmental periods when interventions are maximally effective. Effective interventions can also help us to identify targets for future interventions in order to make sure that each portion of an intervention contributes to adaptive functioning.

\section{Conclusion}

The field of developmental psychopathology has made extensive progress in incorporating biology and multiple levels of functioning, documenting developmental cascades, and creating interventions that interrupt maladaptive cascades following early stress. However, there is still a great deal that we must learn to understand the progression of typical and atypical development, which will require a better integration of 
genetics, biology, behavior, emotion, cognition, context, and culture longitudinally. We also must develop, implement, and test interventions that consider individual differences and the environment across development in order to learn more about the nature of development and to support children who have experienced early stress.

\section{Acknowledgments}

F32HD088029 to Jenalee Doom and a Klaus J. Jacobs Research Prize to Dante Cicchetti.

\section{References}

Andersen, S. L., Tomada, A., Vincow, E. S., Valente, E., Polcari, A., \& Teicher, M. H. (2008). Preliminary evidence for sensitive periods in the effect of childhood sexual abuse on regional brain development. The Journal of Neuropsychiatry and Clinical Neurosciences, 20(3), 292-301. doi:10.1176/appi.neuropsych.20.3.292

Bale, T. L., \& Epperson, C. N. (2015). Sex differences and stress across the lifespan. Nature Neuroscience, 18(10), 1413.

Binder, E. B., Bradley, R. G., Liu, W., Epstein, M.P., Deveau, T. C., Mercer, K. B., .. Ressler, K. J. (2008). Association of fkbp5 polymorphisms and childhood abuse with risk of posttraumatic stress disorder symptoms in adults. Journal of the American Medical Association, 299(11), 1291-1305. doi:10.1001/jama.299.11.1291

Bogdan, R., Hyde, L., \& Hariri, A. (2013). A neurogenetics approach to understanding individual differences in brain, behavior, and risk for psychopathology. Molecular Psychiatry, 18(3), 288-299.

Bosch, N. M., Riese, H., Reijneveld, S. A., Bakker, M. P., Verhulst, F. C., Ormel, J., \& Oldehinkel, A. J. (2012). Timing matters: Long term effects of adversities from 
prenatal period up to adolescence on adolescents' cortisol stress response. The TRAILS study. Psychoneuroendocrinology, 37(9), 1439-1447.

doi:10.1016/j.psyneuen.2012.01.013

Boyce, W. T., \& Ellis, B. J. (2005). Biological sensitivity to context: I. An evolutionarydevelopmental theory of the origins and functions of stress reactivity. Development and Psychopathology, 17(2), 271-301.

Bruce, J., Tarullo, A. R., \& Gunnar, M. R. (2009). Disinhibited social behavior among internationally adopted children. Development and Psychopathology, 21(1), 157171.

Buka, S. L., Stichick, T. L., Birdthistle, I., \& Earls, F. J. (2001). Youth exposure to violence: prevalence, risks, and consequences. American Journal of Orthopsychiatry, 71(3), 298.

Caspi, A., McClay, J., Moffitt, T. E., Mill, J., Martin, J., Craig, I. W., . . Poulton, R. (2002). Role of genotype in the cycle of violence in maltreated children. Science, 297(5582), 851-854. doi:10.1126/science.1072290

Causadias, J. M. (2013). A roadmap for the integration of culture into developmental psychopathology. Development and Psychopathology, 25(4pt2), 1375-1398.

Chang, L., Schwartz, D., Dodge, K. A., \& McBride-Chang, C. (2003). Harsh parenting in relation to child emotion regulation and aggression. Journal of Family Psychology, 17(4), 598.

Chang, S., Walker, S., Grantham-McGregor, S., \& Powell, C. (2002). Early childhood stunting and later behaviour and school achievement. Journal of Child Psychology and Psychiatry, 43(6), 775-783. 
Chisholm, K. (1998). A three year follow-up of attachment and indiscriminate friendliness in children adopted from Romanian orphanages. Child Development, 69(4), 1092-1106.

Cicchetti, D. (2010). Resilience under conditions of extreme stress: A multilevel perspective. World Psychiatry, 9(3), 145-154.

Cicchetti, D. (2013). Annual research review: Resilient functioning in maltreated children - past, present, and future perspectives. Journal of Child Psychology and Psychiatry, 54(4), 402-422.

Cicchetti, D. (2015). Neural plasticity, sensitive periods, and psychopathology. Development and Psychopathology, 27(2), 319.

Cicchetti, D. (Ed.) (2016a). Developmental Psychopathology (Vol. 1, Theory and Method, 3rd ed.). New York: Wiley.

Cicchetti, D. (Ed.) (2016b). Developmental Psychopathology (Vol. 2, Developmental Neuroscience, 3rd ed.). New York: Wiley.

Cicchetti, D. (Ed.) (2016c). Developmental Psychopathology (Vol. 3, Maladaptation and Psychopathology, 3rd ed.). New York: Wiley.

Cicchetti, D. (Ed.) (2016d). Developmental Psychopathology (Vol. 4, Risk, Resilience, and Intervention, 3rd ed.). New York: Wiley.

Cicchetti, D., \& Dawson, G. (2002). Multiple levels of analysis. Development and Psychopathology, 14(3), 417-420.

Cicchetti, D., Hetzel, S., Rogosch, F. A., Handley, E. D., \& Toth, S. L. (2016). Genomewide DNA methylation in 1-year-old infants of mothers with major depressive 
disorder. Development and Psychopathology, 28(4pt2), 1413-1419. doi:10.1017/S0954579416000912

Cicchetti, D., \& Rogosch, F. A. (1996). Equifinality and multifinality in developmental psychopathology. Development and Psychopathology, 8(4), 597-600. doi:10.1017/S0954579400007318

Cicchetti, D., Rogosch, F. A., \& Oshri, A. (2011). Interactive effects of CRHR1, 5HTTLPR, and child maltreatment on diurnal cortisol regulation and internalizing symptomatology. Development and Psychopathology, 23(4), 1125-1138. doi:10.1017/S0954579411000599

Cicchetti, D., \& Schneider-Rosen, K. (1986). An organizational approach to childhood depression. In Depression in young people: Developmental and clinical perspectives (pp. 71-134). New York, NY: Guilford Press.

Cicchetti, D., \& Toth, S. L. (1995). A developmental psychopathology perspective on child abuse and neglect. Journal of the American Academy of Child \& Adolescent Psychiatry, 34(5), 541-565.

Cicchetti, D., \& Tucker, D. (1994). Development and self-regulatory structures of the mind. Development and Psychopathology, 6(4), 533-549.

Cicchetti, D., \& Valentino, K. (2006). An ecological-transactional perspective on child maltreatment: Failure of the average expectable environment and its influence on child development. In Developmental psychopathology (2nd ed.) (pp. 129-201). New York, NY.

Cicchetti, D., \& Walker, E. F. (2003). Neurodevelopmental mechanisms in psychopathology. New York, NY: Cambridge University Press. 
Coldwell, J., Pike, A., \& Dunn, J. (2006). Household chaos-links with parenting and child behaviour. Journal of Child Psychology and Psychiatry, 47(11), 1116-1122.

Colvert, E., Rutter, M., Beckett, C., Castle, J., Groothues, C., Hawkins, A., . . SonugaBarke, E. J. (2008). Emotional difficulties in early adolescence following severe early deprivation: Findings from the English and Romanian adoptees study. Development and Psychopathology, 20(2), 547-567.

Compas, B. E., Orosan, P. G., \& Grant, K. E. (1993). Adolescent stress and coping: Implications for psychopathology during adolescence. Journal of Adolescence, 16(3), 331-349.

Cowell, R. A., Cicchetti, D., Rogosch, F. A., \& Toth, S. L. (2015). Childhood maltreatment and its effect on neurocognitive functioning: Timing and chronicity matter. Development and Psychopathology, 27(2), 521-533.

Cox, M. J., Mills-Koonce, R., Propper, C., \& Gariépy, J.-L. (2010). Systems theory and cascades in developmental psychopathology. Development and Psychopathology, 22(3), 497-506.

De Bellis, M. D. (2001). Developmental traumatology: The psychobiological development of maltreated children and its implications for research, treatment, and policy. Development and Psychopathology, 13(3), 539-564.

De Bellis, M. D., \& Keshavan, M. S. (2003). Sex differences in brain maturation in maltreatment-related pediatric posttraumatic stress disorder. Neuroscience \& Biobehavioral Reviews, 27(1), 103-117.

Del Giudice, M., Ellis, B. J., \& Shirtcliff, E. A. (2011). The adaptive calibration model of stress responsivity. Neuroscience \& Biobehavioral Reviews, 35(7), 1562-1592. 
Doom, J. R., Cicchetti, D., Rogosch, F. A., \& Dackis, M. N. (2013). Child maltreatment and gender interactions as predictors of differential neuroendocrine profiles. Psychoneuroendocrinology, 38(8), 1442-1454. doi:10.1016/j.psyneuen.2012.12.019

Doom, J. R., \& Gunnar, M. R. (2016). Institutional deprivation and neurobehavioral development in infancy. In Environmental experience and plasticity of the developing brain (pp. 185-214). New York, NY: Wiley.

Doom, J. R., VanZomeren-Dohm, A. A., \& Simpson, J. A. (2016). Early unpredictability predicts increased adolescent externalizing behaviors and substance use: A life history perspective. Development and Psychopathology, 28(4pt2), 1505-1516.

Doyle, O., Harmon, C. P., Heckman, J. J., \& Tremblay, R. E. (2009). Investing in early human development: Timing and economic efficiency. Economics and Human Biology, 7(1), 1-6. doi:10.1016/j.ehb.2009.01.002

East, P., Delker, E., Lozoff, B., Delva, J., Castillo, M., \& Gahagan, S. (2017). Associations among infant iron deficiency, childhood emotion and attention regulation, and adolescent problem behaviors. Child Development. doi:10.1111/cdev.12765

Egeland, B., Carlson, E., \& Sroufe, L. A. (1993). Resilience as process. Development and Psychopathology, 5(4), 517-528.

Ellis, B. J., Bianchi, J., Griskevicius, V., \& Frankenhuis, W. E. (2017). Beyond risk and protective factors: An adaptation-based approach to resilience. Perspectives on Psychological Science, 12(4), 561-587. 
Esposito, E. A., Jones, M. J., Doom, J. R., MacIsaac, J. L., Gunnar, M. R., \& Kobor, M. S. (2016). Differential DNA methylation in peripheral blood mononuclear cells in adolescents exposed to significant early but not later childhood adversity.

Development and Psychopathology, 28(4pt2), 1385-1399. doi:10.1017/S0954579416000055

Evans, G. W., \& English, K. (2002). The environment of poverty: Multiple stressor exposure, psychophysiological stress, and socioemotional adjustment. Child Development, 73(4), 1238-1248.

Evans, G. W., Gonnella, C., Marcynyszyn, L. A., Gentile, L., \& Salpekar, N. (2005). The role of chaos in poverty and children's socioemotional adjustment. Psychological Science, $16(7), 560-565$.

Fearon, R., Bakermans-Kranenburg, M. J., Van IJzendoorn, M. H., Lapsley, A. M., \& Roisman, G. I. (2010). The significance of insecure attachment and disorganization in the development of children's externalizing behavior: A metaanalytic study. Child Development, 81(2), 435-456.

Ford, D. H., \& Lerner, R. M. (1992). Developmental systems theory: An integrative approach. Thousand Oaks, CA: Sage.

Frankenhuis, W. E., \& de Weerth, C. (2013). Does early-life exposure to stress shape or impair cognition? Current Directions in Psychological Science, 22(5), 407-412.

Fries, A. B. W., \& Pollak, S. D. (2004). Emotion understanding in postinstitutionalized Eastern European children. Development and Psychopathology, 16(2), 355-369. doi:10.1017/S0954579404044554 
Galler, J. R., \& Ramsey, F. (1989). A follow-up study of the influence of early malnutrition on development: Behavior at home and at school. Journal of the American Academy of Child \& Adolescent Psychiatry, 28(2), 254-261.

Gardner, J. M., Walker, S. P., Powell, C. A., \& Grantham-McGregor, S. (2003). A randomized controlled trial of a home-visiting intervention on cognition and behavior in term low birth weight infants. The Journal of Pediatrics, 143(5), 634 639.

Goldmann, E., \& Galea, S. (2014). Mental health consequences of disasters. Annual Review of Public Health, 35, 169-183.

Gorman-Smith, D., Henry, D. B., \& Tolan, P. H. (2004). Exposure to community violence and violence perpetration: The protective effects of family functioning. Journal of Clinical Child and Adolescent Psychology, 33(3), 439-449.

Gorman-Smith, D., \& Tolan, P. H. (2003). Positive adaptation among youth exposed to community violence. In Resilience and vulnerability: Adaptation in the context of childhood adversities (pp. 392-413). New York, NY: Cambridge University Press.

Gorman-Smith, D., \& Tolan, P. (1998). The role of exposure to community violence and developmental problems among inner-city youth. Development and Psychopathology, 10(1), 101-116.

Graves, P. (1978). Nutrition and infant behavior: A replication study in the Katmandu Valley, Nepal. The American Journal of Clinical Nutrition, 31(3), 541-551.

Grigg, J. (2004). Environmental toxins; their impact on children's health. Archives of Disease in Childhood, 89(3), 244-250. doi:10.1136/adc.2002.022202 
Groh, A. M., Roisman, G. I., van IJzendoorn, M. H., Bakermans-Kranenburg, M. J., \& Fearon, R. P. (2012). The significance of insecure and disorganized attachment for children's internalizing symptoms: A meta-analytic study. Child Development, 83(2), 591-610.

Hackman, D. A., Farah, M. J., \& Meaney, M. J. (2010). Socioeconomic status and the brain: Mechanistic insights from human and animal research. Nature Reviews. Neuroscience, 11(9), 651.

Hankin, B. L., Abramson, L. Y., Moffitt, T. E., Silva, P. A., McGee, R., \& Angell, K. E. (1998). Development of depression from preadolescence to young adulthood: Emerging gender differences in a 10-year longitudinal study. Journal of Abnormal Psychology, 107(1), 128.

Hanna-Attisha, M., LaChance, J., Sadler, R. C., \& Champney Schnepp, A. (2016). Elevated blood lead levels in children associated with the Flint drinking water crisis: A spatial analysis of risk and public health response. American Journal of Public Health, 106(2), 283-290.

Hardt, J., \& Rutter, M. (2004). Validity of adult retrospective reports of adverse childhood experiences: Review of the evidence. Journal of Child Psychology and Psychiatry, 45(2), 260-273.

Heckman, J. J. (2006). Skill formation and the economics of investing in disadvantaged children. Science, 312(5782), 1900-1902.

Heim, C., Bradley, B., Mletzko, T. C., Deveau, T. C., Musselman, D. L., Nemeroff, C. B., . . Binder, E. B. (2009). Effect of childhood trauma on adult depression and 
neuroendocrine function: Sex-specific moderation by CRH Receptor 1 Gene.

Frontiers in Behavioral Neuroscience, 3, 41. doi:10.3389/neuro.08.041.2009

Herrenkohl, T. I., Kosterman, R., Mason, W. A., Hawkins, J. D., McCarty, C. A., \& McCauley, E. (2010). Effects of childhood conduct problems and family adversity on health, health behaviors, and service use in early adulthood: Tests of developmental pathways involving adolescent risk taking and depression. Development and Psychopathology, 22(3), 655-665. doi:10.1017/S0954579410000349

Howe, G. W., Reiss, D., \& Yuh, J. (2002). Can prevention trials test theories of etiology? Development and Psychopathology, 14(4), 673-694.

Hubel, D. H., \& Wiesel, T. N. (1962). Receptive fields, binocular interaction and functional architecture in the cat's visual cortex. The Journal of Physiology, 160(1), 106-154.

Humphreys, K. L., Lee, S. S., Telzer, E. H., Gabard-Durnam, L. J., Goff, B., Flannery, J., \& Tottenham, N. (2015). Exploration-exploitation strategy is dependent on early experience. Developmental Psychobiology, 57(3), 313-321.

Juffer, F., \& van IJzendoorn, M. H. (2009). International adoption comes of age:

Development of international adoptees from a longitudinal and meta-analytical perspective. In International advances in adoption research for practice (pp. 169192). Wiley-Blackwell: West Sussex, UK.

Juster, R.-P., McEwen, B. S., \& Lupien, S. J. (2010). Allostatic load biomarkers of chronic stress and impact on health and cognition. Neuroscience \& Biobehavioral Reviews, 35(1), 2-16. doi:https://doi.org/10.1016/j.neubiorev.2009.10.002 
Kandel, E. R. (1998). A new intellectual framework for psychiatry. American Journal of Psychiatry, 155(4), 457-469.

Kar, N. (2009). Psychological impact of disasters on children: Review of assessment and interventions. World Journal of Pediatrics, 5(1), 5-11.

Kim, P., Evans, G. W., Angstadt, M., Ho, S. S., Sripada, C. S., Swain, J. E., . . Phan, K. L. (2013). Effects of childhood poverty and chronic stress on emotion regulatory brain function in adulthood. Proceedings of the National Academy of Sciences, 110(46), 18442-18447.

Knudsen, E. I. (2004). Sensitive periods in the development of the brain and behavior. Journal of Cognitive Neuroscience, 16(8), 1412-1425.

Kolb, B., \& Whishaw, I. Q. (1998). Brain plasticity and behavior. Annual Review of Psychology, 49(1), 43-64.

Lee, C., Tsenkova, V., \& Carr, D. (2014). Childhood trauma and metabolic syndrome in men and women. Social Science \& Medicine (1982), 105, 122-130. doi:10.1016/j.socscimed.2014.01.017

Lozoff, B., Beard, J., Connor, J., Felt, B., Georgieff, M., \& Schallert, T. (2006). Longlasting neural and behavioral effects of iron deficiency in infancy. Nutrition Reviews, 64, S34-S43. doi:10.1111/j.1753-4887.2006.tb00243.x

Lozoff, B., Smith, J. B., Kaciroti, N., Clark, K. M., Guevara, S., \& Jimenez, E. (2013). Functional significance of early-life iron deficiency: Outcomes at 25 years. Journal of Pediatrics, 163(5), 1260-1266. doi:10.1016/j.jpeds.2013.05.015 
Lupien, S. J., McEwen, B. S., Gunnar, M. R., \& Heim, C. (2009). Effects of stress throughout the lifespan on the brain, behaviour and cognition. Nature Reviews Neuroscience, 10(6), 434-445.

Luthar, S. S., Cicchetti, D., \& Becker, B. (2000). The construct of resilience: A critical evaluation and guidelines for future work. Child Development, 71(3), 543-562.

Martinez, P., \& Richters, J. E. (1993). The NIMH community violence project: II. Children's distress symptoms associated with violence exposure. Psychiatry, 56(1), 22-35.

Massart, R., Nemoda, Z., Suderman, M. J., Sutti, S., Ruggiero, A. M., Dettmer, A. M., . . . Szyf, M. (2016). Early life adversity alters normal sex-dependent developmental dynamics of DNA methylation. Development and Psychopathology, 28(4pt2), 1259-1272. doi:10.1017/S0954579416000833

Masten, A. S. (2001). Ordinary magic: Resilience processes in development. American Psychologist, 56(3), 227.

Masten, A. S. (2014). Global perspectives on resilience in children and youth. Child Development, 85(1), 6-20.

Masten, A. S., \& Cicchetti, D. (2010). Developmental cascades. Development and Psychopathology, 22(3), 491.

Masten, A. S., \& Cicchetti, D. (2016). Resilience in development: Progress and transformation. In Developmental psychopathology (pp. 271-333). Hoboken, NJ: John Wiley \& Sons, Inc. 
Masten, A. S., \& Narayan, A. J. (2012). Child development in the context of disaster, war, and terrorism: Pathways of risk and resilience. Annual Review of Psychology, 63.

Masten, A. S., Roisman, G. I., Long, J. D., Burt, K. B., Obradović, J., Riley, J. R., . . . Tellegen, A. (2005). Developmental cascades: Linking academic achievement and externalizing and internalizing symptoms over 20 years. Developmental Psychology, 41(5), 733. doi:10.1037/0012-1649.41.5.733

Maughan, B., \& Rutter, M. (1997). Retrospective reporting of childhood adversity: issues in assessing long-term recall. Journal of Personality Disorders, 11(1), 19-33.

McEwen, B. S. (1998). Stress, adaptation, and disease: Allostasis and allostatic load. Annals of the New York Academy of Sciences, 840(1), 33-44. doi:10.1111/j.17496632.1998.tb09546.x

McEwen, B. S., \& Seeman, T. (1999). Protective and damaging effects of mediators of stress: Elaborating and testing the concepts of allostasis and allostatic load. Annals of the New York Academy of Sciences, 896(1), 30-47.

McGowan, P. O., Sasaki, A., D’Alessio, A. C., Dymov, S., Labonté, B., Szyf, M., .. . Meaney, M. J. (2009). Epigenetic regulation of the glucocorticoid receptor in human brain associates with childhood abuse. Nature Neuroscience, 12(3), 342348. doi:10.1038/nn.2270

Merz, E. C., \& McCall, R. B. (2010). Behavior problems in children adopted from psychosocially depriving institutions. Journal of Abnormal Child Psychology, 38(4), 459-470. doi:10.1007/s10802-009-9383-4 
Mills-Koonce, W. R., Willoughby, M. T., Garrett-Peters, P., Wagner, N., VernonFeagans, L., \& Investigators, F. L. P. K. (2016). The interplay among socioeconomic status, household chaos, and parenting in the prediction of child conduct problems and callous-unemotional behaviors. Development and Psychopathology, 28(3), 757-771.

Mittal, C., Griskevicius, V., Simpson, J. A., Sung, S., \& Young, E. S. (2015). Cognitive adaptations to stressful environments: When childhood adversity enhances adult executive function. Journal of Personality and Social Psychology, 109(4), 604621.

Mogg, K., \& Bradley, B. P. (1998). A cognitive-motivational analysis of anxiety. Behaviour Research and Therapy, 36(9), 809-848.

Monk, C., Georgieff, M. K., \& Osterholm, E. A. (2013). Research review: Maternal prenatal distress and poor nutrition-mutually influencing risk factors affecting infant neurocognitive development. Journal of Child Psychology and Psychiatry, 54(2), 115-130. doi:10.1111/jcpp.12000

Murgatroyd, C., Patchev, A. V., Wu, Y., Micale, V., Bockmühl, Y., Fischer, D., . . Spengler, D. (2009). Dynamic DNA methylation programs persistent adverse effects of early-life stress. Nature Neuroscience, 12(12), 1559-1566.

Murry, V. M., Brown, P. A., Brody, G. H., Cutrona, C. E., \& Simons, R. L. (2001). Racial discrimination as a moderator of the links among stress, maternal psychological functioning, and family relationships. Journal of Marriage and Family, 63(4), 915-926. 
Naumova, O. Y., Lee, M., Koposov, R., Szyf, M., Dozier, M., \& Grigorenko, E. L. (2012). Differential patterns of whole-genome DNA methylation in institutionalized children and children raised by their biological parents. Development and Psychopathology, 24(1), 143-155.

Nederhof, E., \& Schmidt, M. V. (2012). Mismatch or cumulative stress: Toward an integrated hypothesis of programming effects. Physiology \& Behavior, 106(5), 691-700.

Needleman, H. L., Gunnoe, C., Leviton, A., Reed, R., Peresie, H., Maher, C., \& Barrett, P. (1979). Deficits in psychologic and classroom performance of children with elevated dentine lead levels. New England Journal of Medicine, 300(13), 689695.

Nolen-Hoeksema, S. (2001). Gender differences in depression. Current Directions in Psychological Science, 10(5), 173-176.

Pachter, L. M., \& Garcia Coll, C. (2009). Racism and child health: A review of the literature and future directions. Journal of Developmental and Behavioral Pediatrics: JDBP, 30(3), 255-263. doi:10.1097/DBP.0b013e3181a7ed5a Peyrot, W. J., Milaneschi, Y., Abdellaoui, A., Sullivan, P. F., Hottenga, J. J., Boomsma, D. I., \& Penninx, B. W. (2014). Effect of polygenic risk scores on depression in childhood trauma. The British Journal of Psychiatry, 205(2), 113-119.

Pine, D. S., Mogg, K., Bradley, B. P., Montgomery, L., Monk, C. S., McClure, E., . . Kaufman, J. (2005). Attention bias to threat in maltreated children: Implications for vulnerability to stress-related psychopathology. American Journal of Psychiatry, 162(2), 291-296. 
Priest, N., Paradies, Y., Trenerry, B., Truong, M., Karlsen, S., \& Kelly, Y. (2013). A systematic review of studies examining the relationship between reported racism and health and wellbeing for children and young people. Social Science \& Medicine, 95, 115-127.

Rhee, S. H., \& Waldman, I. D. (2002). Genetic and environmental influences on antisocial behavior: A meta-analysis of twin and adoption studies. Psychological Bulletin, 128(3), 490.

Richardson, S., Birch, H., Grabie, E., \& Yoder, K. (1972). The behavior of children in school who were severely malnourished in the first two years of life. Journal of Health and Social Behavior, 13(3), 276-284.

Romens, S. E., McDonald, J., Svaren, J., \& Pollak, S. D. (2015). Associations between early life stress and gene methylation in children. Child Development, 86(1), 303309.

Roth, T. L., Lubin, F. D., Funk, A. J., \& Sweatt, J. D. (2009). Lasting epigenetic influence of early-life adversity on the BDNF gene. Biological Psychiatry, 65(9), 760-769. doi:10.1016/j.biopsych.2008.11.028

Roth, T. L., \& Sweatt, J. D. (2011). Epigenetic mechanisms and environmental shaping of the brain during sensitive periods of development. Journal of Child Psychology and Psychiatry, and Allied Disciplines, 52(4), 398-408. doi:10.1111/j.14697610.2010.02282.x

Sedlak, A. J., Mettenburg, J., Basena, M., Peta, I., McPherson, K., \& Greene, A. (2010). Fourth national incidence study of child abuse and neglect (NIS-4). Washington, DC: US Department of Health and Human Services. 
Shonkoff, J. P., Boyce, W. T., \& McEwen, B. S. (2009). Neuroscience, molecular biology, and the childhood roots of health disparities: Building a new framework for health promotion and disease prevention. Journal of the American Medical Association, 301(21), 2252-2259. doi:10.1001/jama.2009.754

Shonkoff, J. P., Garner, A. S., Siegel, B. S., Dobbins, M. I., Earls, M. F., McGuinn, L., . . . Care, D. (2012). The lifelong effects of early childhood adversity and toxic stress. Pediatrics, 129(1), e232-e246. doi:10.1542/peds.2011-2663

Simpson, J. A., Griskevicius, V., Kuo, S. I., Sung, S., \& Collins, W. A. (2012). Evolution, stress, and sensitive periods: The influence of unpredictability in early versus late childhood on sex and risky behavior. Developmental Psychology, 48(3), 674.

Spencer, M. B., Noll, E., Stoltzfus, J., \& Harpalani, V. (2001). Identity and school adjustment: Revisiting the "acting White" assumption. Educational Psychologist, $36(1), 21-30$.

Sroufe, L. A. (1979). The coherence of individual development: Early care, attachment, and subsequent developmental issues. American Psychologist, 34(10), 834.

Sroufe, L. A. (1990). Considering normal and abnormal together: The essence of developmental psychopathology. Development and Psychopathology, 2(4), 335347.

Sternberg, K. J., Baradaran, L. P., Abbott, C. B., Lamb, M. E., \& Guterman, E. (2006). Type of violence, age, and gender differences in the effects of family violence on children's behavior problems: A mega-analysis. Developmental Review, 26(1), $89-112$. 
Stiles, J., \& Jernigan, T. L. (2010). The basics of brain development. Neuropsychology Review, 20(4), 327-348.

Sullivan, P. F., Neale, M. C., \& Kendler, K. S. (2000). Genetic epidemiology of major depression: Review and meta-analysis. American Journal of Psychiatry, 157(10), $1552-1562$.

Szyf, M., \& Bick, J. (2013). DNA methylation: A mechanism for embedding early life experiences in the genome. Child Development, 84(1), 49-57. doi:10.1111/j.14678624.2012.01793.x

Teicher, M. H., Andersen, S. L., Polcari, A., Anderson, C. M., Navalta, C. P., \& Kim, D. M. (2003). The neurobiological consequences of early stress and childhood maltreatment. Neuroscience \& Biobehavioral Reviews, 27(1), 33-44.

Teicher, M. H., Tomoda, A., \& Andersen, S. L. (2006). Neurobiological consequences of early stress and childhood maltreatment: Are results from human and animal studies comparable? Annals of the New York Academy of Sciences, 1071(1), 313323.

Toth, S. L., Rogosch, F. A., Manly, J. T., \& Cicchetti, D. (2006). The efficacy of toddlerparent psychotherapy to reorganize attachment in the young offspring of mothers with major depressive disorder: A randomized preventive trial. Journal of Consulting and Clinical Psychology, 74(6), 1006.

Troller-Renfree, S., Zeanah, C. H., Nelson, C. A., \& Fox, N. A. (2018). Neural and cognitive factors influencing the emergence of psychopathology: Insights from the Bucharest Early Intervention Project. Child Development Perspectives, 12(1), 28-33. 
Tsankova, N., Renthal, W., Kumar, A., \& Nestler, E. J. (2007). Epigenetic regulation in psychiatric disorders. Nature Reviews Neuroscience, 8(5), 355-367.

Van den Dries, L., Juffer, F., van IJzendoorn, M. H., \& Bakermans-Kranenburg, M. J. (2009). Fostering security? A meta-analysis of attachment in adopted children. Children and Youth Services Review, 31(3), 410-421.

Van Praag, H., Kempermann, G., \& Gage, F. H. (2000). Neural consequences of environmental enrichment. Nature Reviews Neuroscience, 1(3), 191.

Vanderwert, R. E., Marshall, P. J., Nelson III, C. A., Zeanah, C. H., \& Fox, N. A. (2010). Timing of intervention affects brain electrical activity in children exposed to severe psychosocial neglect. PLoS One, 5(7), e11415.

Walker, S. P., Chang, S. M., Powell, C. A., Simonoff, E., \& Grantham-McGregor, S. M. (2007). Early childhood stunting is associated with poor psychological functioning in late adolescence and effects are reduced by psychosocial stimulation. Journal of Nutrition, 137(11), 2464-2469.

Weaver, I. C., Cervoni, N., Champagne, F. A., D’Alessio, A. C., Sharma, S., Seckl, J. R., . . Meaney, M. J. (2004). Epigenetic programming by maternal behavior. Nature Neuroscience, 7(8), 847-854. doi:10.1038/nn1276

Wolfe, D. A., Crooks, C. V., Lee, V., McIntyre-Smith, A., \& Jaffe, P. G. (2003). The effects of children's exposure to domestic violence: A meta-analysis and critique. Clinical Child and Family Psychology Review, 6(3), 171-187.

Zeanah, C., Egger, H. L., Smyke, A. T., Nelson, C. A., Fox, N. A., Marshall, P. J., \& Guthrie, D. (2009). Institutional rearing and psychiatric disorders in Romanian preschool children. American Journal of Psychiatry, 166(7), 777-785. 
Zeanah, C., Gunnar, M. R., McCall, R. B., Kreppner, J. M., \& Fox, N. A. (2011).

Sensitive Periods. Monographs of the Society for Research in Child Development, 76(4), 147-162. doi:10.1111/j.1540-5834.2011.00631.x

Zeidner, M., \& Saklofske, D. (1996). Adaptive and maladaptive coping. In M. Zeidner \& N. S. Endler (Eds.), Handbook of coping: Theory, research, applications (pp. 505-531). Oxford, England: John Wiley \& Sons.

Zhang, T.Y., \& Meaney, M. J. (2010). Epigenetics and the environmental regulation of the genome and its function. Annual Review of Psychology, 61, 439-466. 